\title{
Chapter 5 \\ Nature-Based Solutions Accelerating Urban Sustainability Transitions in Cities: Lessons from Dresden, Genk and Stockholm Cities
}

\author{
Niki Frantzeskaki, Sara Borgström, Leen Gorissen, Markus Egermann, \\ and Franziska Ehnert
}

\begin{abstract}
Nature based solutions are amongst other practices that transition initiatives work with when intervening in their place and change its fabric. Focusing on the actors establishing, driving and scaling these solutions in and across cities, we come to evince that nature-based solutions have transformative social impact since they mediate new social relations and new social configurations contributing to social innovation in cities, and change nature perception and human-nature relations in urban contexts. We built from evidence in three city-regions that over the past years they saw the proliferation of community-based and policy-based initiatives with the aim to improve sustainability, livability and the aspiration to foster inclusivity and social justice in their cities: the city of Dresden in Germany, the city of Genk in Belgium and the city-region of Stockholm in Sweden. We will elaborate on the different ways nature based solutions as practices of transition initiatives in cities get scaled and contribute to accelerating sustainability transitions in these city-regions. In line with this, we will draw cross-case lessons for urban planning on the tensions transition initiatives that experiment with and institutionalize nature-based solutions in their cities face when actively pursue acceleration strategies and pathways to scale.
\end{abstract}

N. Frantzeskaki $(\bowtie)$

Dutch Research Institute For Transitions (DRIFT), Erasmus University Rotterdam,

Rotterdam, The Netherlands

e-mail: n.frantzeskaki@drift.eur.nl

S. Borgström

School of Architecture and the Built Environment, KTH Royal Institute of Technology,

Stockholm, Sweden

e-mail: sara.borgstrom@abe.kth.se

L. Gorissen

Flemish Institute of Technological Research (VITO), Mol, Belgium

e-mail: leen.gorissen@vito.be

M. Egermann • F. Ehnert

Leibniz Institute of Ecological Urban and Regional Development (IOER), Dresden, Germany

e-mail:m.egermann@ioer.de; f.ehnert@ioer.de

N. Kabisch et al. (eds.), Nature-based Solutions to Climate Change Adaptation

in Urban Areas, Theory and Practice of Urban Sustainability Transitions,

DOI 10.1007/978-3-319-56091-5_5 
Keywords Cities - Sustainability transitions - Transformations - Scaling • Acceleration • Institutions $\bullet$ Governance $\bullet$ Transition initiatives $\bullet$ Civil society $\bullet$ Learning

\subsection{Introduction}

Cities are places and spaces of sustainability transitions: where solutions can be created, tested, and scaled (Coenen and Truffer 2012; Wolfram and Frantzeskaki 2016). In urban contexts, we found that actor configurations position themselves through practice and belief and often create new realities worth investigating in view of amounting unsustainability pressures. In our research we cast an eye on transition initiatives, actor collectives led by public, civic, business or partnerships of those, who put in place new ways of doing, thinking and organizing and transform current systems of provision with the aim to actively contribute to environmental sustainability. Understanding how these actor configurations play out with local governments, businesses and how they change the 'rules of the game' in cities is a governance question upon which we reflect. Especially in view of how they can influence the pace of change to more sustainable practices, lifestyles and living in cities of the future (Romero-Lankao 2012).

In recent years, sustainability transition studies have identified transition initiatives as the seeds of local transformation (Seyfang and Smith 2007; Seyfang et al. 2014) looking closely on the ways they create new practices, new narratives and understandings of sustainabilities as well as viewing how they transform infrastructure systems (Reeves et al. 2014). Civil society-led transition initiatives have been examined closely by scholars to assess their transformative potential, and it is the local understanding and local knowledge that civil society has that catalyzes the "tailoring to local context" and consequently leads to a fast-paced realization of new ideas and new approaches for more socially responsible governance (Aylett 2010, 2013, p. 869). Civil society can advocate for more radical and progressive ideas rather than "returning to old ideals" (cf. Calhoun 2012, p. 27). These characteristics of rapid experimentation adapted to the local context make civil society function as a driver of sustainability transitions (Boyer 2015; Burggraeve 2015; Bussu and Bartels 2014; Calhoun 2012; Carmin et al. 2003; Cerar 2014; Christmann 2014; Creamer 2015; Foo et al. 2015; Forrest and Wiek 2015; Fuchs and Hinderer 2014; Garcia et al. 2015; Kothari 2014; Magnani and Osti 2016; Seyfang and Smith 2007; Seyfang and Longhurst 2013; Seyfang et al. 2014; Touchton and Wampler 2014; Verdini 2015; Zajontz and Laysens 2015; Walker et al. 2014; Warshawsky 2014; Wagenaar and Healey 2015).

When investigating how transition initiatives change urban space and urban systems of provision, we found that a great number of those initiatives put in place and experiment with solutions that restore nature, imitate and build upon nature processes as ways to address environmental issues in place-explicit ways, known as nature-based solutions. Nature-based solutions have been defined as living solutions 
underpinned by natural processes and structures that are designed to address various environmental challenges while simultaneously providing economic, social, and environmental benefits (European Commission 2015). Nature-based solutions as social-spatial interventions have a transformative impact in the relations between people and nature. First, nature-based solutions contribute in the mental and physical health and wellbeing of people in cities (Andersson et al. 2015; Ambrey and Fleming 2014, p. 1298; Bratman et al. 2015; Buchel and Frantzeskaki 2015; Carrus et al. 2015). Reconnecting with nature in cities can contribute to social ties, establishment of sense of community and social cohesion (Kazmierczak 2013). Second, nature-based solutions are systemic ways on locally responding to climate change pressures. So far research has focused on the (potential) insurance value of naturebased solutions that revolves around the restorative capacity of these solutions deeming them effective for climate change adaptation and mitigation (Green et al. 2016; Haase et al. 2012; Kabisch et al. 2016; Mullaney et al. 2015; Andersson et al. Chap. 4 this volume). We add to this understanding is that nature-based solutions can have regenerative impact (Carrus et al. 2015, p. 226).

We argue that for understanding the impact of nature-based solutions in cities, we need to attend to their social production (Ernston 2013). In this way, we will understand how nature-based solutions as social-spatial settings, they mediate the need and ability of actors and communities to establish a positive dependence of place motivating them to restore it (Tidball and Stedman 2012, p. 297). Third, transition initiatives are instrumental in creating and localizing nature-based solutions, moving from a passive experience 'of nature' to an active experience 'with (making) nature'. In this way, transition initiatives experiment with nature-based solutions, learn-by-doing on how to adapt them to city-specific and place-specific situations and geophysical characteristics and create new narratives and understandings of their benefits. As thus, nature-based solutions are seeds of transformation of local practice and local space towards more sustainable ones.

In line with the above, nature-based solutions as social-ecological settings require social actors and social processes to be implemented in cities. In this chapter we examine the way nature-based solutions scale as a social process that includes transition initiatives driving their social production. Specifically, we examine, how transition initiatives as actor configurations that establish, experiment and localise nature-based solutions shift them from 'solutions' to social configurations, making nature-based solutions the new 'urban commons of sustainability' and in this way contributing to accelerating sustainability transitions in cities.

\subsection{Understanding the Acceleration Dynamics of Urban Sustainability Transitions}

We describe transition initiatives which drive transformative change towards environmental sustainability in an accelerated pace, or simply transition initiatives that actively contribute to accelerating urban sustainability transitions. The latter is 
understood as contributing to conditions of balance, resilience and interconnectedness that allows society to satisfy its needs without exceeding the capacity of its supporting ecosystems to continue to regenerate the services to meet those needs and without diminishing biodiversity. The initiatives under study all undertake activities that in one way or another support, promote, maintain, develop or upscale nature-based solutions.

We investigate the way transition initiatives operate in accelerating urban transition initiatives with nature-based solutions with a conceptual framework of acceleration mechanisms developed as the core of a 3 year EU funded research project ARTS (www.acceleratingtransitions.eu). The conceptual framework of the mechanisms driving accelerating of urban sustainability transitions is not to "be taken as a recipe for success" of how transition initiatives should relate and connect but "as handles for reflective practice" that in the context of multi-level governance can instigate accumulation of changes and increase the pace of changes required for urban sustainability transitions to take-off (Bussu and Bartels 2014). Building from the literature of sustainability transitions (Rotmans et al. 2001, p. 17; Van der Brugge and Van Raak 2007; Avelino and Rotmans 2011) and urban governance and with a focus on transformative agency working (Westley et al. 2013 p. 2; Olsson et al. 2014; Cote and Nightingale 2012), we propose five mechanisms that may contribute to acceleration of sustainability transitions and we selectively present the most recent writings that ground our conceptualization and further show the applicability of our conceptualization in understanding accelerating dynamics in cities.

Upscaling is the growth of members, supporters or users of a single transition initiative in order to spread these new ways of thinking, organizing and practicing. Boyer (2015, p. 322) identifies scaling up as a diffusion pathway of grassroots innovations focusing on a scaling of a practice by referring to "application of practice beyond an activist core, to a broader audience". Desa and Koch (2014) identifies the diffusion and spread of one product or practice to greater number of users as a scaling and Staggenborg, and Ogrodnik (2015) point at different ways that transition initiatives meaningfully scale up in broadening participation and engagement of new members and supporters without compromising values and operation models.

Replicating is the take up of new ways of doing, organizing and thinking of one transition initiative by another transition initiative or different actors in order to spread out these new ways. Garcia et al. (2015, p. 96) recognizes replication of innovative practices as a process that contributes to systemic change, further backing our conceptualization as a process for changing the pace of change in transitions. Boyer (2015, p. 322) identifies replication as a diffusion pathway of grassroots innovations addressing "spread through a network of dedicated activists" and later on, as "diffusion of practice with a committed activist network".

Partnering is the pooling and/or complementing of resources, competences, and capacities in order to exploit synergies to support and ensure the continuity of the new ways of doing, organizing and thinking. Partnering is the mechanism that describes the ways transition initiatives act for pooling synergies and leverage 
resources (Horsford and Sampson 2014, p. 961; Frantzeskaki et al. 2014; Garcia et al. 2015) and establishing partnerships as catalytic for change (Eckerberg et al. 2015). Partnering in the form of public-private partnerships occur to provide specific services "in the realms of public health, development and environment" (Borzel and Risse 2010, p. 120; Healey 2015). Partnering allows collective learning and tackling inequality in place-based projects via new actor collaborations (Devolder and Block 2015) and for seeking resources to sustain the initiative itself (Healey 2015, p. 111; Sagaris 2014).

The majority of research writings on impact of transition initiatives to sustainability transitions focused on site-specific impact and majorly under-examine the impact in context dynamics including governance. In our conceptual framework we include two mechanisms to describe and capture the way transition initiatives play out with the city context dynamics: Embedding and Instrumentalising.

Instrumentalising is tapping into and capitalizing on opportunities provided by the multi-level governance context of the city-region in order to forge resources for the continuity of the operation of the initiative. Chmutina et al. (2014) note that the ability of transition initiatives to capitalize on opportunities also relies on the existence of 'openness' situations within multi-level governance for change and for empowering transition initiatives. Acquiring resources is vital for sustaining the activities of the initiative that can also include regeneration of deprived areas (Fraser and Kick 2014, p. 1447; Healey 2015, p. 115) and for growing beyond a "talking shop" (Forrest and Wiek 2015).

Embedding is the alignment of old and new ways of doing, organizing and thinking in order to integrate them into city-regional governance patterns. Bussu and Bartels (2014) point at embedding engagement and conflict resolution practices from community to the city governance and as a way of "formalizing" community projects and participation methods (also addressed by Barr et al. 2011). Embedding involves the alignment of efforts, strategies and agendas/goals between transition initiatives and local government across scales (Horsford and Sampson 2014, p. 961; Garcia et al. 2015). Embedding is enabled by the recognition from the public sector to alter practices and be more responsive and receptive/dialectic to innovative practices coming from other actors (Boyer 2015, p. 322; Healey 2015; Healey and Vigar 2015; Frantzeskaki and Kabisch 2016). Overall, embedding captures the extent to which transition initiatives strategically shape the context in which they operate (Moss et al. 2014).

\subsection{Case Studies}

In the ARTS project we conduct transdisciplinary research with transition initiatives in a number of transition city-regions to collectively explore, and assess accelerating dynamics. We selected five transition city-regions in which we see signs of acceleration in the form of accumulated changes in policy, planning and civil 
society, and a booming number of transition initiatives in place that pressure the status quo with provoking sustainability practices, ideas and ways of organization. These city-regions include: Brighton in the UK, Budapest in Hungary, Dresden in Germany, Genk in Belgium, and Stockholm in Sweden. In this chapter we only present case study findings and cross-case study analysis of three of the city-regions as indicative where a critical mass of transition initiatives practicing and localizing nature-based solutions' exist and actively contribute to accelerating transitions.

\subsubsection{The City-Region of Dresden, Germany}

Dresden is a growing city of approximately 549.000 inhabitants in 2015 in the East of Germany. It is the capital of the Free State of Saxony. Leaving behind the communist past with the democratic transition of 1989/90, the environmental movement could organize and act freely. Even though the City of Dresden displays many unsustainable patterns, this gave birth to a plethora of local initiatives that promote alternative, sustainable ways of fulfilling human basic needs. The City of Dresden joined the European Climate Alliance in 1994 and committed to reducing its carbon footprint to a sustainable level of 2.5 tonnes of GHG emissions per capita by 2080 .

\subsubsection{Nature-Based Solutions Initiatives in the City-Region Dresden}

In 2016, there are almost 100 local initiatives that strive for a sustainable future. They display a considerable diversity of approaches, covering domains such as food production and consumption, building and urban development, mobility and transport, energy production and consumption, biodiversity protection or environmental education. Many of them pursue nature-based solutions and combine them with social and economic innovations to foster a socio-ecological transition.

Urban Gardening Network Dresden This umbrella organization was established in 2012 to link all the different garden projects within the city-region of Dresden. About two dozen of these kinds of projects with various backgrounds and concepts exist. Among them are community gardens, intercultural and multigenerational gardens, community supported agricultures as well as beekeeping initiatives. The network wants to link the already existing community gardens to support not only green infrastructure within the city, but also to encourage the creation of spaces for learning and experimenting. The objectives of the network are (1) the support of cooperation activities between the (mostly civil society-driven) gardening initiatives and the city-administration, (2) to generate synergies between the urban gardens, like by sharing tools or seeds (3) to exchange know-how and experience, and, (4) to collectively organize workshops, educational programs to raise public awareness for issues related to sustainable food production, green spaces, and biodiversity. The network understands itself as part of a bigger movement, promoting sustainable food production. 
Consumer Cooperative for Organic Products This consumer cooperative (VG Verbrauchergemeinschaft für umweltgerecht erzeugte Produkte eG) is one of the biggest local cooperatives for organic food in Germany. With more than 9.000 members, the initiative plays a crucial role in offering Dresden residents a relatively easy option to buy organic food, but also daily goods (detergent, shampoo, etc.). In addition, the VG is well linked with many small sustainable producers in the cityregion of Dresden. It helps them to be become much more known (e.g. a shop for natural colours). The VG was established in 1991 with its first rooms located at the Environmental Center Dresden and just a few members. Most of the contacts to the regional suppliers of organic food have existed for years and nowadays they are supplied by more than 80 farms and producers located nearby (production and further processing is provided within a radius of $150 \mathrm{~km}$ around the city-region). In 1994, the initiative established an association. In 2005, the economic part of the initiative was transferred into a cooperative structure. Due to the non-profit character of the cooperative, members pay lower prices on regional organic food. This is possible because membership fees cover overheads so that members have to pay only the producer price without an additional add-up of retailing. Nowadays, there are five different shops of the initiative, whereby four of them offer also non-members the opportunity to buy the offered goods, but to a higher retailing price. To re-connect producers and consumers, members can join annual guided tours to visit the suppliers of the VG.

Hufewiesen e.V. The initiative Hufewiesen is named after a unique area of 13 ha forest and meadow landscape located in the historical center of the district of Dresden-Pieschen (populated by about 50.000 inhabitants). Over the course of generations, the residents used the area as farmland. Yet, in 1990, the City Council of Dresden classified the Hufewiesen as prospective building land. Thereafter, the parcels of land were purchased by a real estate company and laid fallow ever since. When the company wanted to build on the entire area, the citizen initiative Hufewiesen formed in order to preserve the land as a common green space that is owned and managed by the citizens themselves ("Bürgergrün") since the Hufewiesen is the last green space in the district Dresden-Pieschen. In so doing, it builds on the idea of commoning. The initiative formed in 2012. It built up a large supporter network and organized a great variety of events and activities. It managed to raise awareness not only among civil society networks, but also in local politics and public administration as well as in the science and business community. In 2014, it started a large participation process, conducting a citizen survey with over 1.200 people, to develop a new concept for the area. The survey clearly showed that the majority of the people wants to preserve the area as a nearby recreation area and a green space accessible to the public. Participants proposed a mosaic of different sustainable uses (e.g. community gardening, children's playground, sports field, etc.). Currently, the initiative debates how to acquire ownership of the land and transform it into a common green space ("Bürgergrün"), for instance by creating a foundation. 


\subsubsection{Accelerating Dresden's Transition with Nature-Based Solutions' Initiatives}

The three initiatives described above use nature-based solutions and environmental sustainability in different ways and different fields of actions (gardening, food and nature conservation). Hence, they also contribute to the acceleration of urban sustainability transitions in different ways.

The Urban Gardening Network evolved into a hub for acceleration in the food domain. Since the network was established in 2012, many more community gardens were founded in Dresden. This is due to the network's active work on spreading the idea of urban gardening, for instance by organizing the educational program 'Seitentriebe'. It offers manifold courses on cultivation, the conservation of food or herbalist education. All new community gardens participate in this program and spread the idea further. Due to this network character, the community gardeners were able to establish informal contacts and formal cooperation with the city administration (The Office for Green Space) and the Association of Dresden Allotment Gardens. ${ }^{1}$ Based on this cooperation, they now jointly plan a 'living lab' in which single former allotment gardens are transformed into community gardens, then existing right next to each other within one site.

The VG contributes to acceleration in different ways. First of all, it does so simply by increasing the number of members. It not only managed to upscale its members to over 9.000, but also to attract citizens from different backgrounds, also reaching beyond the "green bubble of already committed people". More importantly, it could induce a co-evolution process of organic farming around the cityregion. Most of the VG's suppliers converted from conventional to organic farming as they were encouraged, but also obliged to do so by the VG. These organic farmers benefit from the VG because it creates a constant demand for their organic produce. Without the VG, many of them would not be able to survive at normal market conditions. In so doing, it has a very important stabilizing function for local ecological farmers.

It is worth mentioning that the three presented initiatives, but also many other nature-oriented initiatives in Dresden seek to combine environmentalism with social activism. They put a high emphasis on participation, sharing and commons as values of its own. Against this background, the Hufewiesen contributes to promoting NBS by reconnecting citizens with the values of urban nature. They succeeded in gathering a considerable amount of citizens behind the association's objectives of nature protection and nature-based development and in changing the perspective of local politicians. With its initiative, it could shield the urban green from massive building investments so far (Photos 5.1, 5.2, 5.3 and 5.4).

\footnotetext{
${ }^{1}$ This represents about 55.000 allotment gardens in the city-region of Dresden.
} 


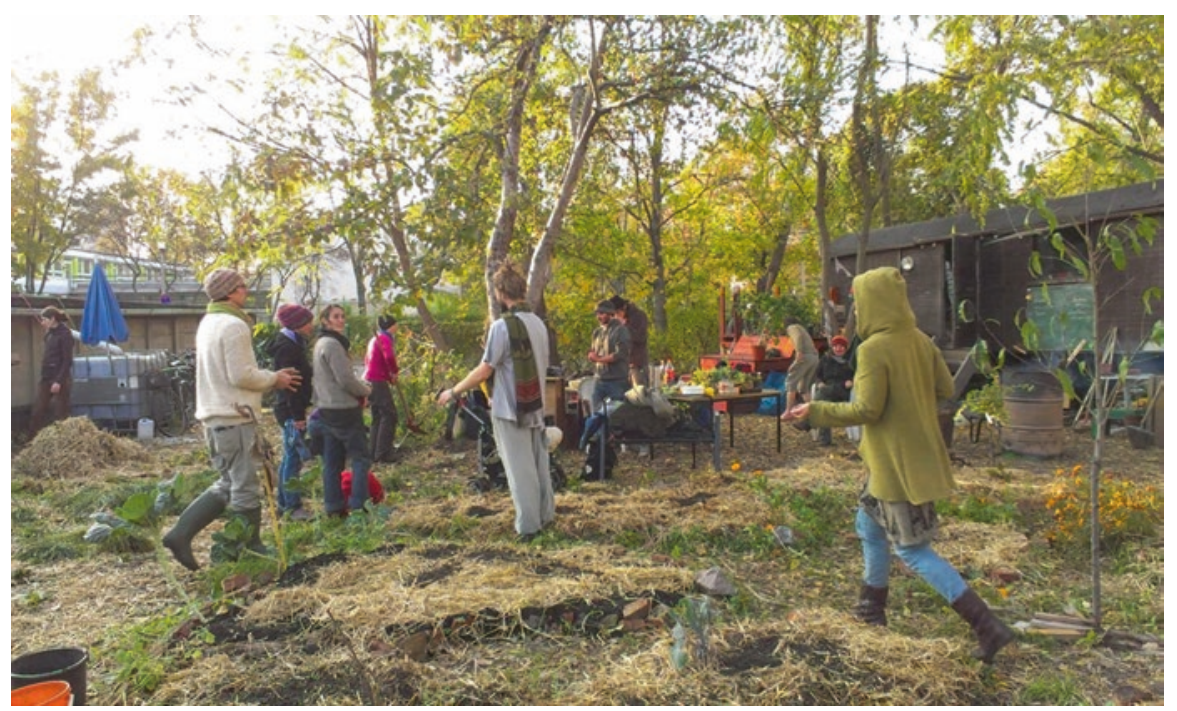

Photo 5.1 Community Garden Dresden Johannstadt (Gartennetzwerk - cc license)

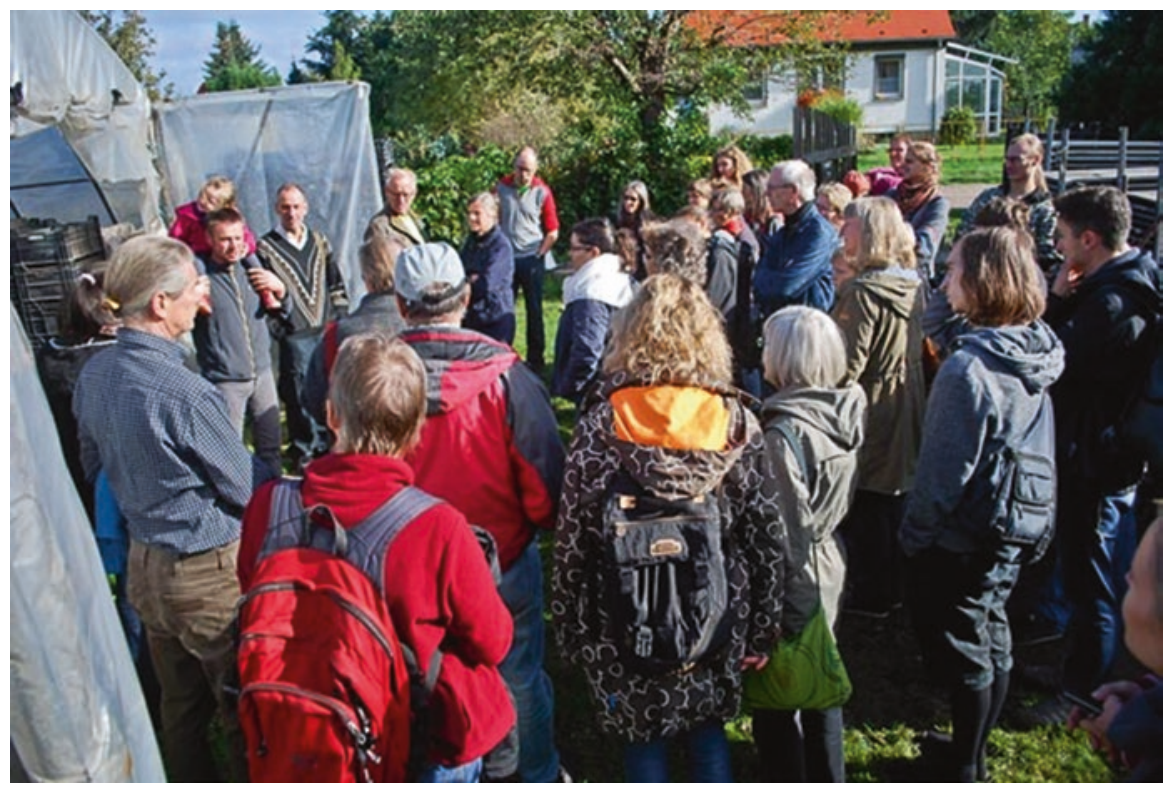

Photo 5.2 Guided tour of VG members to their suppliers of organic regional food, Dresden, Germany (VG Busfahrt - Olaf Stiebitz) 


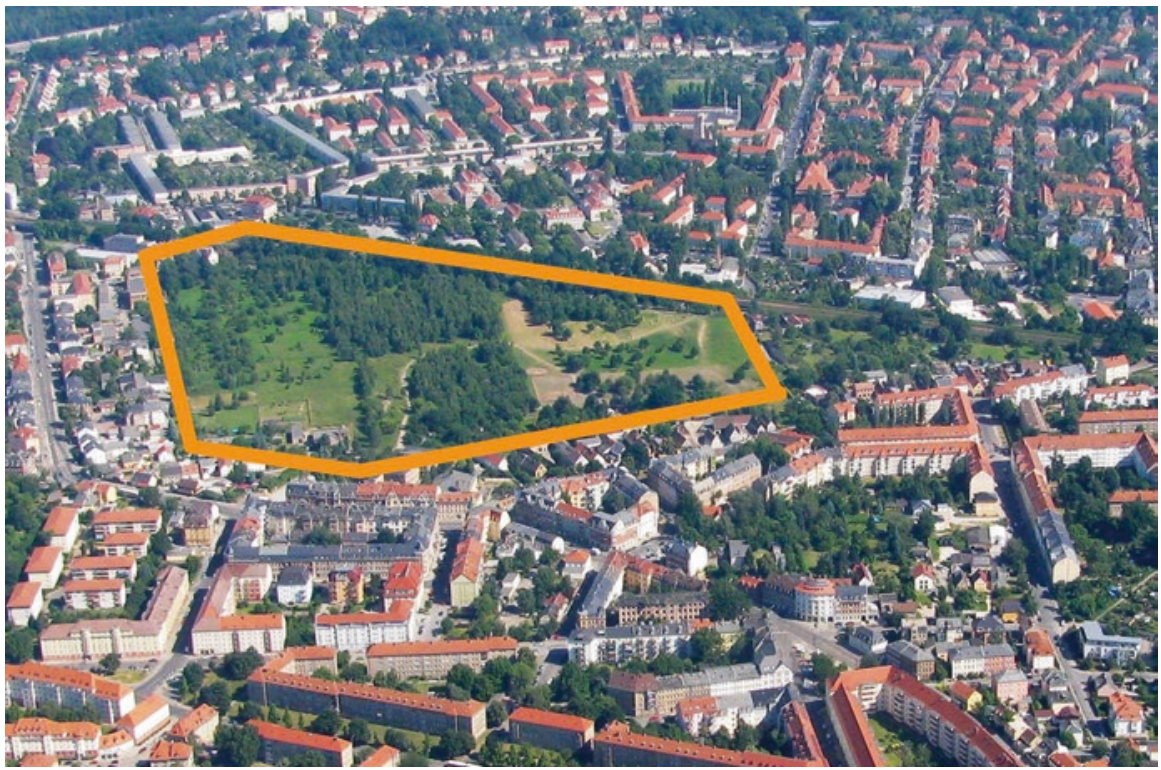

Photo 5.3 Hufewiesen I: Air picture of the Hufewiesen area - with this picture the initiative convinced many inhabitants of the value of the site and nature in the city, Dresden, Germany (Hufeweisen - cc license)

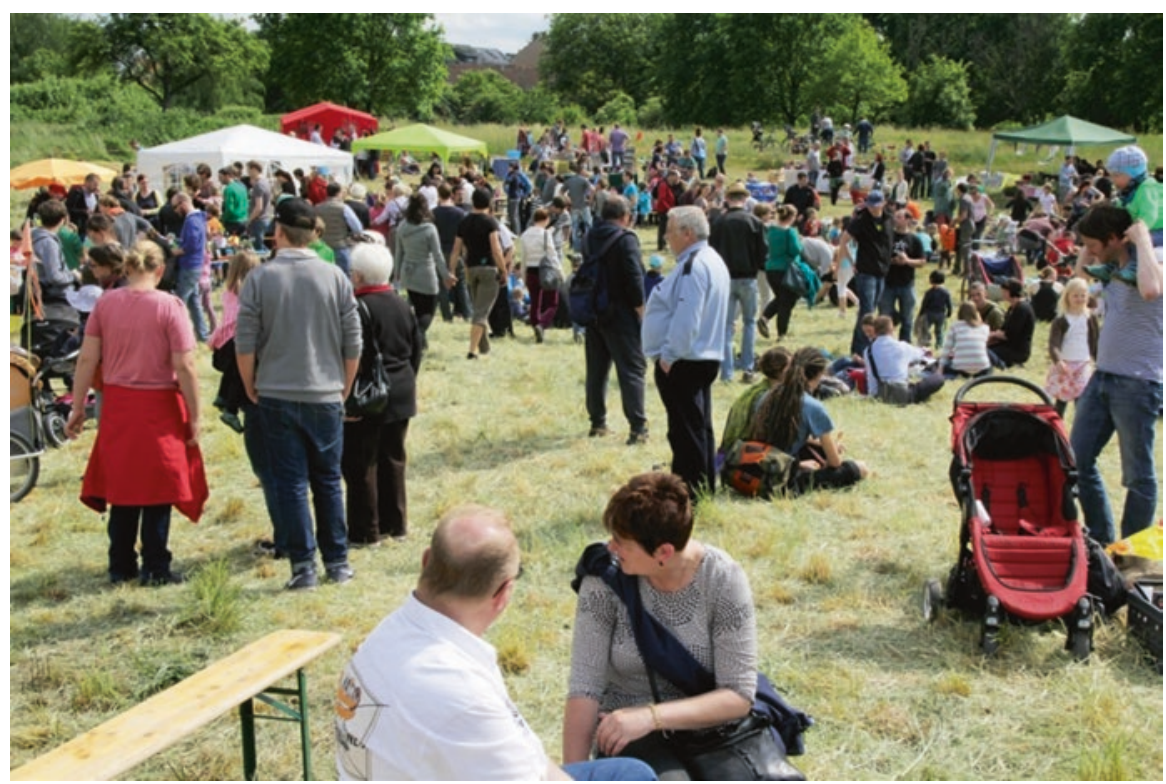

Photo 5.4 Hufewiesen II: Once a year, the Hufewiesen initiative invites inhabitants to experience and celebrate the urban green space they would like to protect, Dresden, Germany (Hufeweisen cc license) 


\subsubsection{Genk Case, Belgium}

Genk is the greenest city of Flanders in Belgium, housing a multicultural population of approximately 65000 inhabitants. It shares the characteristics of European postindustrial cities that have gone through economic restructuring and are searching for a new identity. The City has an extraordinary history of experimentation on the front of social innovation and is at the moment in the middle of rethinking its economic backbone.

\subsubsection{Nature-Based Solutions' Initiatives in the City Region}

Genk also houses a variety of local volunteers that are active in environmental sustainability. Several transition initiatives aim to change nature perceptions, reinforce human-nature relationships or promote eco-friendly lifestyles and practices. Below we highlight a couple of initiatives that are active in promoting or supporting naturebased solutions:

The Heempark The Heemparkis a unique example of a Public - Civic Partnership as it combines city supported (Environment and Nature Centre) and volunteer activities (Heempark vzw) in a collaborative and mutually beneficial way. The Heempark was initiated in 1985 by a group of local volunteers who aimed to safeguard the local agricultural heritage through the Heempark model - a combination of demo sites of local agricultural practice with a clear focus on environmental sustainability. When the number of visitors increased and the entire initiative grew over the heads of the volunteers, the City supported with personnel, infrastructure and an educational program for schools and associations. At the moment the Heempark has about 90 members and approximately 35 active volunteers that maintain the gardens and organise a wide variety of activities to promote reconnection of people to nature and increase environmental awareness and engagement. Activities include cooking classes of organic food with autistic children, sessions about herbs, bees and vegetables, making honey, building eco-friendly gardens and so on. Our findings show that the Heempark is a hotspot when it comes to connecting initiatives and reconnecting people to nature. It houses 350 educational groups while attracting approximately 10.000 visitors a year (Photo 5.5).

The Bee Plan The Bee plan is a multi-stakeholder initiative to turn the city of Genk into a bee friendly city. It originated in 2013 when two concerned citizens organised an open environmental council meeting showcasing the documentary 'More than honey'. Afterwards, the 60 people present brainstormed about what they could do in the city to improve conditions for bees and all ideas were gathered. To take this further, a working group was set up involving beekeepers, city services, environmental organisations and engaged civilians who developed a 'Bee plan' for the city of Genk that was approved by the bench of aldermen in February 2014. The plan aims to strengthen the bee populations in the city region by (1) improving the 


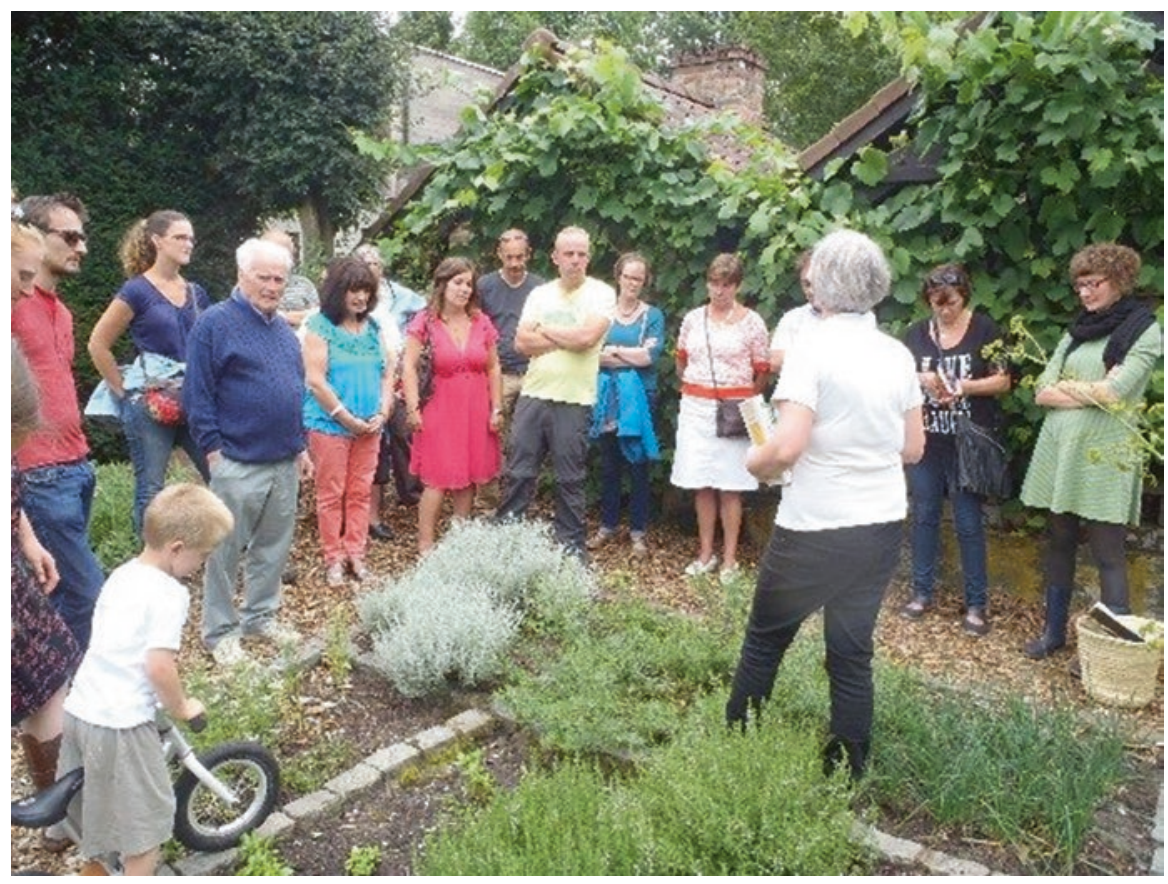

Photo 5.5 A volunteer guiding the Sunday herb walk at the Heempark, Genk, Belgium

living conditions for bees on communal land; (2) by engaging citizens to do the same on their land and (3) supporting local beekeepers. The plan thus aims to combine public and civic action, for instance in setting up a voluntary team of 30 bee ambassadors that participate in many public events, in a bee friendly makeover of public spaces, in organizing educational activities such as bees in the library etc. The Bee plan thus originated from a multi-actor brainstorm and developed into a policy plan coordinated by the City through the Heempark but in close cooperation with a wide range of volunteers (e.g. Bee Team) to restore and regenerate nature to place (Photos 5.6, 5.7 and 5.8).

Velt Genk \& the Local Organic Allotment Gardens Velt Genk, the Guild for Ecofriendly Lifestyles and Organic Gardening, is a local section of the Flemish Velt vzw organisation. Velt vzw is a non-profit organisation that was founded in 1974 by a group of concerned citizens that wanted to make the agricultural sector healthier and more environmentally friendly by banning chemical pesticides and fertilizers. Gradually, the field of action shifted to private (vegetable) gardening. Velt vzw supported local citizens in Genk in the renewal project to convert the decayed allotment gardens into vibrant organic food production systems. The project, building on strong collaborative partnerships, proved to be so successful that it gave rise to a Flemish fund allowing replication all over Flanders. The local branch, Velt Genk was established in 1978 - thus being one of the oldest divisions of Velt vZW - and has currently 
Photo 5.6 A volunteer of the Bee team shows how to make honey at the Heempark, Genk, Belgium
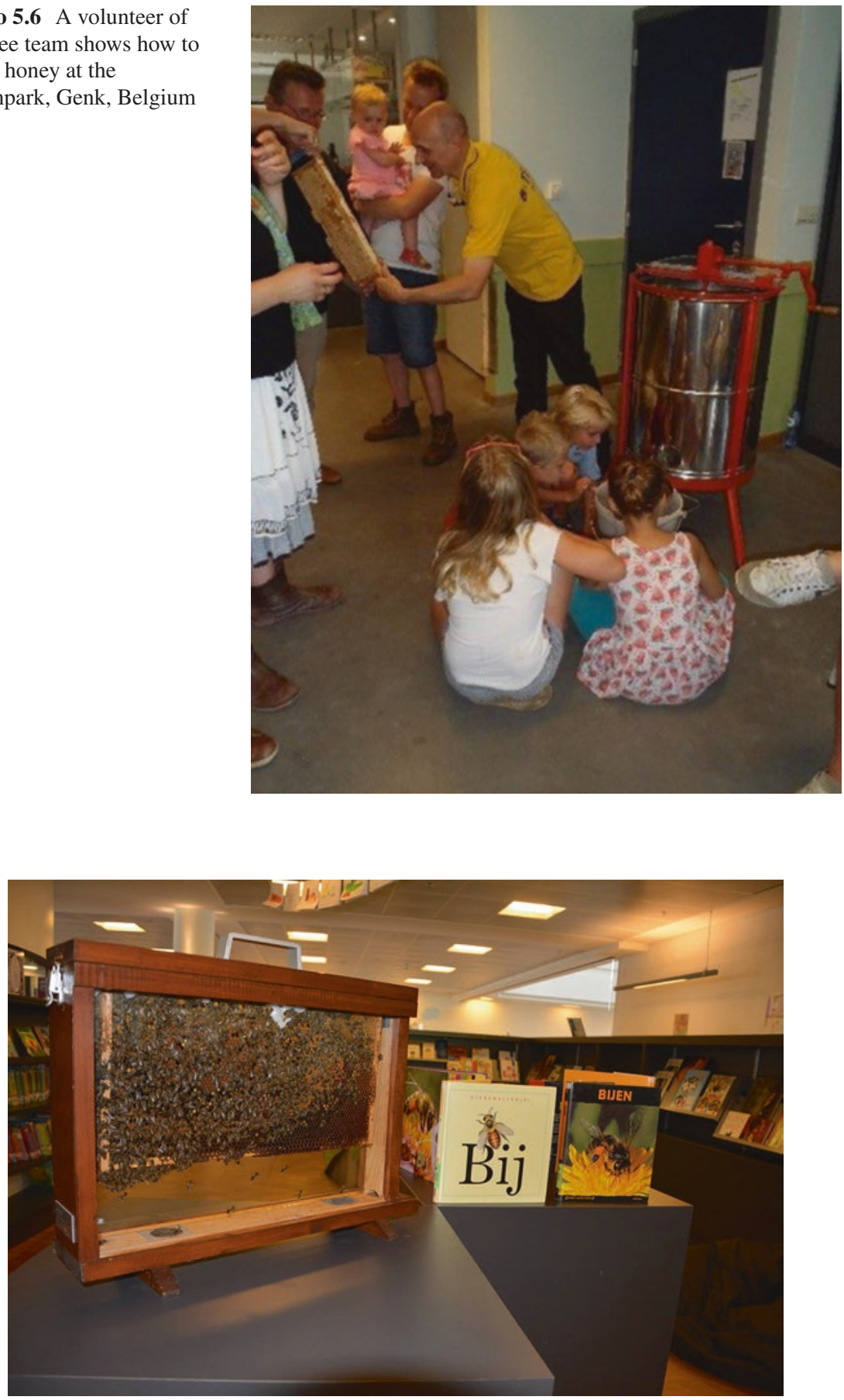

Photo 5.7 Bees in the Library in Genk, Belgium 


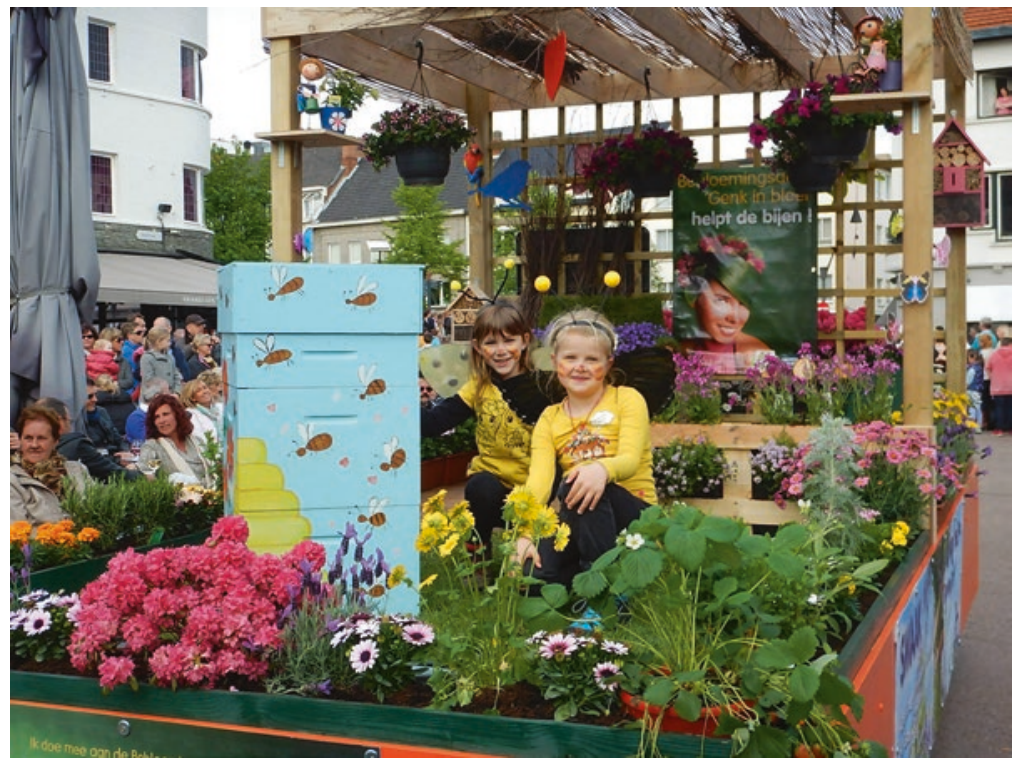

Photo 5.8 Bee mobile with children in Genk, Belgium

more than 100 members. Volunteers from Velt Genk are involved in several other initiatives associated with environmental sustainability such as the newly established communal garden 'Tuin van Betty', they maintain a demonstration garden at the Heempark, initiate and support vegetable growing in centres for the elderly and local volunteers are active in the Organic allotment garden of Genk Noord. Velt Genk successfully campaigned to ban harmful pesticides from public green management. With their 'Without is healthier' campaign they convinced the mayor to sign an intention declaration spurring eco-friendly public green management.

\subsubsection{Accelerating Genk's Transition with Nature-Based Solutions' Initiatives}

The initiatives described above are all in one way or another bringing nature-based solutions into practice, either by converting vacant land into organic allotment gardens, by turning Genk into a bee friendly city, by setting up and maintaining demo sites showcasing and promoting environmentally friendly practices (e.g. compost schools, bee towers, organic vegetable gardens). They promote reconnection of citizens to nature by organizing a wide range of activities, localize nature to place by involving citizens in the restoration and regeneration of nature in the city. What is more, our findings indicate that these initiatives contribute to accelerating sustainability transitions by spreading nature-based thinking and doing, mobilizing people and money and changing governance institutions. These transformative and 
community-based initiatives thereby trigger social-ecological reconfigurations that safeguard/promote ecological functions and thus play an instrumental role in fueling systemic change (Gorissen et al. 2017).

\subsubsection{Stockholm Case, Sweden}

The urbanized parts of the Stockholm city-region consist of an urban mosaic of interwoven green-blue and grey structures. Nature is seen as an important landscape element has a strong foundation in Swedish culture and traditions, which is apparent in the many protected nature and outdoor recreation areas within and in close proximity to Swedish cities. However, besides these protected remains of a more natural landscape, other nature-based solutions have just recently gained interest, especially in relation to climate change challenges, e.g. run off water management. The Stockholm population of approximately 2 million people is increasing rapidly, creating a severe housing shortage and the urbanization is taking place by densification and sprawl with resulting decrease of larger green space, but also an exploration and demand for other kinds of nature based solutions in the densifying city districts. As of now most of the locally based sustainability initiatives are using the blue-green infrastructure as part of their transition agenda.

\subsubsection{Nature-Based Solutions' Initiatives in the City Region Stockholm}

Miljöverkstan Flaten In 2011 it all started around the bathing place Flatenbadet in a nature reserve of high recreational value in southern Stockholm. The place was falling apart but the founders saw that the place could offer much to the local residents. They wanted to build bridges to the site by giving the children living nearby connections to nature. At the same time, they wanted to pay tribute to the location, care for and nurture the nature, and to activate both children and adults. They started a group together with actors in the area for the revitalisation of Flatenbadet as the venue and contacted the City District Administration (CDA, within Stockholm municipality). The CDA had the opportunity to set aside a small amount of money that was used to design a nature trail for school children and also for doing background research and networking to create a meeting place. From these starting seeds Miljöverkstan Flaten was formed and a huge flow of interest was awakened. Today they work extensively with sustainability by place-making, focusing on local kindergartens, school kids, teenagers and recent immigrants in various projects using the area and local resources. Miljöverkstan Flaten view nature as the prime support of strong and tolerant individuals and hence uses nature experiences in a broad sense to handle and proactively work with social and environmental challenges. Nature is present in all their activities, including organizational meetings and partnership building. Their most important growth takes place by networking that has resulted in the creation of new local initiatives, activated youngsters and established 
a great network linking many parts of the society. In 2016 they became a key partner of a collaborative pilot project initiated by the Stockholm municipality that aims to explore how modern nature protected areas in urbanizing landscapes can be part of a larger transition to urban sustainable development. The Miljöverkstan Flaten use of nature-based solutions is captured by the nature-to-people as well as to localize nature-to-place dimensions.

Stockholm Green Wedges Collaboration From a perceived need to coordinate the 26 local municipalities around the green wedges of Stockholm city-region, NGOs representing environmental protection, tourism, outdoor recreation and cultural heritage formed the network "Protect the green wedges of Metropolitan Stockholm" in 1996. It was triggered by a report about the values of the ten green wedges launched by the Stockholm County Council Planning Division and it was used by the network in local and regional urban development debates. In 2006 the six municipalities and NGOs related to the Rösjö green wedge north of Stockholm were invited to a workshop by the regional branch of Swedish Society for Nature Conservation in order to form a mutual understanding of the green wedge as an ecological unit and hence inspire to cross-border/sector as well as municipal/civic society collaborations. The first steps included joint study visits, workshops, creation of a visitor's map, and building networks with regional authorities and other external key actors and eventually a platform for collaboration was created that also gained political support. At a certain point of concretizing, including work plan and budget, the politicians realized that the municipalities would be the leaders of this initiative. The initiative was then reorganized and the formalization process started, which is generally seen as beneficial. The initiative has gained attention and later became replicated in another green wedge also belonging to one of the initially engaged municipalities. The experiences are now spread to additional green wedges in the city-region and the long term goal of creating a regional green wedge council is coming closer to realization. The first and foremost goal of this initiative is to safeguard a connected regional green structure in the rapidly urbanizing city-region, which can be seen as a traditional nature conservation project. However, the structure that is promoted can on the other hand be seen as the back-bone of many other future NBS in the region since it will support the ecological functionality of smaller structures, e.g. pocket parks and green roofs, whose resilience will be dependent on the vitality of this larger structure. Hence, the green wedge collaborations in Stockholm is primarily about nature-to-people use of nature-based solutions but also has indirect linkages to localize nature-to-place and evidently creates an important ecological support in the urbanized parts of the city in form of restoration and regeneration (Photo 5.9).

Stadsodling Stockholm The founder discovered a communal gardening project in a central park in Stockholm and also people to engage with. They wanted to know more, especially how to do farming in public places. Many plantations were of a temporary nature and it was much disorganized. The idea was that the different urban gardening/farming communities could help each other, so in 2013 they started off with a matching function - helping people with an interest or a project to find 


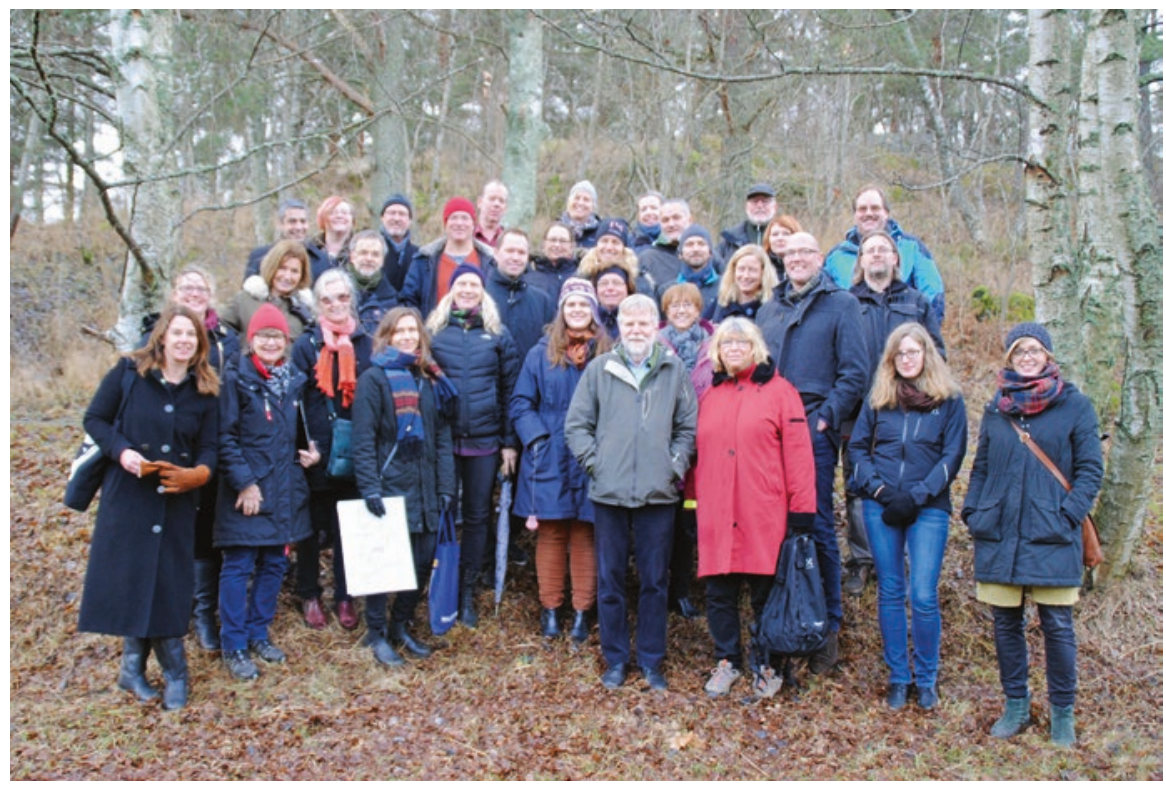

Photo 5.9 Guided tour with all municipal politicians, officials and initiative representatives with the aim to create a shared understanding of their common interests - 2015 in Tyresta green wedge 10 years later, Stockholm, Sweden

each other. In a garden fair, a map over Stockholm was put up and people could pin their plantations to it. It later turned in to a digital map. The emerging network wanted to be a voice, influence and be a contrast to the city. To get permits they needed an organisation so they started an association, however it is mostly on paper, what they do is grow and cultivate. There are several reasons people get active and there are various styles between groups and within groups, e.g. to create community in the town, to produce food autonomously and safe, to protect the environment and make the city greener and more aesthetic. The leaders of the association are nowadays seen as nation leading experts in urban gardening, writing hand books, giving lectures and leading workshops as well as designing new types of urban gardens. In the spring 2014 Sundbyberg municipality was part of a smaller investigation regarding urban gardening and it was nearly nonexistent and the municipality showed very limited interest in the topic. Two years later, in spring 2016, the same municipality has decided to formulate an urban gardening strategy and invited the Stadsodling Stockholm association to arrange a workshop. This initiative is a clear example of restoring and regenerating nature-to-place dimension of NBS (Photo 5.10). 
Photo 5.10 Sundbyberg municipality in Stockholm has decided to formulate a strategy for urban gardening and asks Stadsodling Stockholm to arrange a workshop to get on the right track. (May 2016, Stockholm, Sweden)

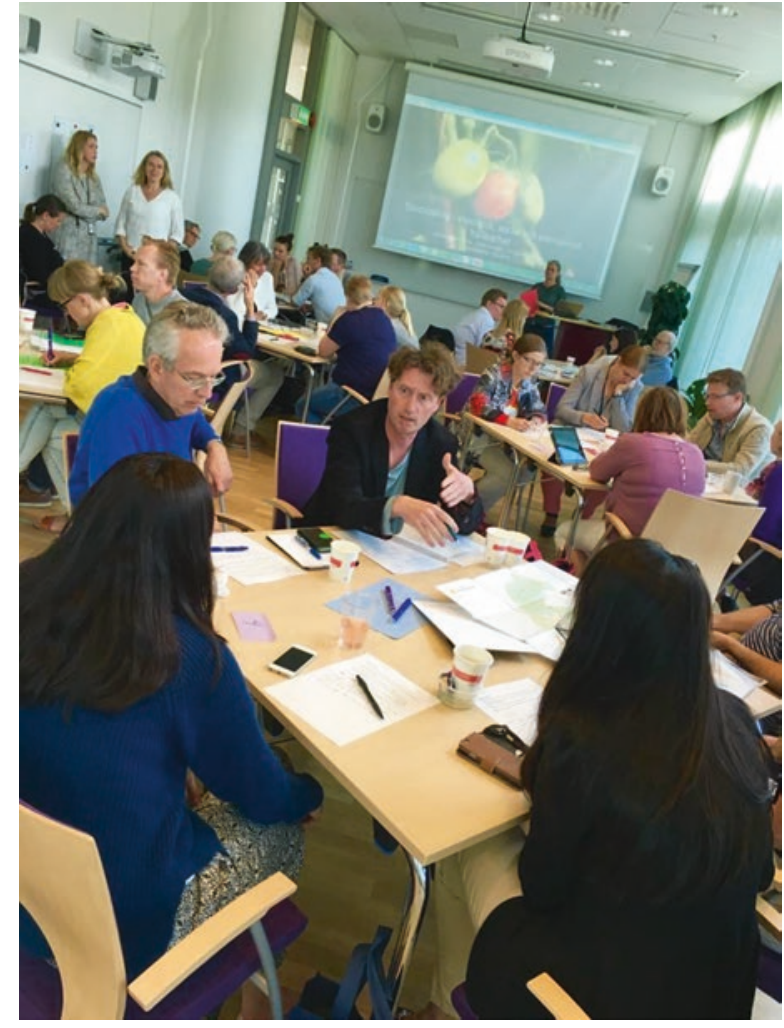

\subsubsection{Accelerating Stockholm's Transition with Nature-Based Solutions' Initiatives}

The linkages to nature is very different in all the three examples of transition initiatives in Stockholm but also in a very direct way link nature to urban challenges such as social unrest, social segregation, food security and access to ecosystem services provided by functional urban green structures. Even if different, one commonality is the importance of collaboration in all three initiatives which is part of their success in accelerating transition to sustainable development in Stockholm city-region.

Miljöverkstan Flaten has created a solid local network as well as a network of significant partners throughout the region. Their well anchored activities both with residents and local authorities have given them legitimacy to represent the Flaten area in the pilot project which will be part of forming how Stockholm municipality will think of, design and maintain their protected areas in the future - potentially activating the replicating mechanism. The most important mechanisms in the case of Miljöverkstan have so far been coupling and embedding. 
Stockholm green wedges collaboration started with the initiative that instrumentalised a policy report which triggered a long term, step-wise partnership process towards embedding into the municipal work. First different local initiatives and associations coupled to form a strong voice and consortium that invited the concerned municipalities. After 5 years this is now fully part of the municipal work and replicated to other similar situations in the city-region. One of the key success factors has been the carefully constructed partnership between different types of actors at different geographical scales. Stadsodling Stockholm aims to activate the mechanism coupling by linking urban gardening initiatives for exchange and power and perhaps also replicating. They are part of the strong emergence of urban gardening and agriculture in the city-region and forcefully seek to change the way these activities are discussed at regional and municipal level - embedding - also by bringing in examples from outside the region.

\subsection{Implications for Accelerating Urban Sustainability Transitions Through Nature-Based Solutions}

For accelerating urban sustainability transitions, social production and mediation of nature-based solutions requires collective agency - transition initiatives- and urban change agents to mediate and catalyse processes of transformation. More specifically, we found that transition initiatives have often depended on a small circle of urban change agents. Especially urban change agents have been central to promoting the activities of transition initiatives in the city-regions. They are a specific type of change agents who act as mediators, translators and networkers between both different sectors (i.e. local government, civil society) and different domains (i.e. food, energy). They can be members of a single or of multiple transition initiatives. They are capable of 'speaking the languages' of different sectors (i.e. public sector, private sector, civil society) and of developing a horizontal, integrated view of several domains, which enables them to identify and support synergies between these domains. They often also act as networkers between the city-region and the governance context and, in doing so, contribute to the diffusion of ideas, knowledge and experience. While on the one hand, these transition entrepreneurs can be important connectors and networkers between transition initiatives, on the other hand, the reliance on these few change agents makes the process of change very fragile. Activities of transition initiatives might decline again if these individuals leave the city-region or become overburdened by their voluntary commitment.

For accelerating urban sustainability transitions, investing in establishing resourceful and capacitated local governments is critical for ensuring productive collaborations and synergies with transition initiatives and ability to recognise the value of nature-based solutions as practices and outcomes of transition initiatives. Another common challenge across the three city-regions includes the insufficient capacities of local governments to establish synergies across domains, like food, education and biodiversity. The limited ability of local governments (local political 
and administrative authorities) to incorporate novelty due to compartmentalisation has been identified as a common obstacle across the city-regions. Local public administration tends to have separate departments each following a distinct administrative specialisation, which is associated with different objectives, legal frameworks and responsibilities. Due to this compartmentalisation, TIs often find it difficult to approach the public administration and find an appropriate contact person if the novel character of their activities does not fit the established specialisation of administrative departments. This in turn hampers their efforts in accelerating a sustainability transition in the city-region. For instance, urban gardening transition initiatives in Dresden and Stockholm reported that they did not fit into the established specialisations of the public administrations of their municipalities, which led to a situation of unclear mandates and specifications. The local governments have, therefore been struggling with integrating these progressive transition initiatives in their work or providing support for them. By contrast, the local government of Genk has taken a very proactive approach. It has recognised the problem and is seeking innovative ways of overcoming compartmentalisation and 'silo politics' to achieve better coordination and policy integration. It is exploring approaches of systems and transition thinking and has introduced a new, horizontal position for sustainability and a transversal transition team.

For accelerating sustainability transitions in cities with and through transition initiatives who experiment and innovate with nature-based solutions, a policy mix is required to support beyond 'seeding' for advancing and enabling transition initiatives to scale. Transition initiatives across the city-regions have reported that the resources available to them such as time, budget, space or political mandate are seen as insufficient, which impedes their activities and, thereby, change towards sustainability. The dependence of many TIs on external funding by the central government has been a major source of instability for the TIs, especially in the present era of austerity, where reduced funding for the voluntary sector generally has caused a loss of momentum of the TIs. In terms of governance, this implies that this projectification of funding should be overcome and more stable funding schemes established. For instance, local governments could create funds for NBS initiatives with a longer time frame. Conversely, the decentralised governance structure of the city-region of Stockholm gives much political autonomy to the municipalities within the cityregion. Here, the political situation depends on the individual municipalities with some of them giving high priority to environmental sustainability and others pursuing different political priorities. TIs from both Dresden and Stockholm report that the trend of a projectification of funding, where most of the funding is short-term and project-based, poses a severe challenge to them because it creates high instability and uncertainty for their activities.

Last but not least, for scaling nature-based solutions to contribute to accelerating sustainability transitions in cities, social and environmental agendas in cities need to connect or exploit synergies more strategically. Nature-based solutions require a social process to be spatially integrated in a city, and produce social benefits in the form of sense of place, empowering communities and establishing ties between social groups. As such, even though on the outset nature-based solutions 
are 'environmental solutions', they produce multiple benefits and with our cases we show that they produce social benefits, addressing social challenges such as segregation and inclusion. Hence, it may be worth noticing that an urban agenda for nature-based solutions is intrinsically an integrated agenda for social and environmental issues.

Acknowledgements This book chapter is based on research carried out as part of the ARTS Project, Accelerating and Rescaling Sustainability Transitions Project funded by the European Union's Seventh Framework Programme (FP7) (grant agreement 603654). The views expressed in this article are the sole responsibility of the authors and do not necessarily reflect the views of the European Union.

\section{References}

Ambrey C, Fleming C (2014) Public greenspace and life satisfaction in urban Australia. Urban Stud 51(6):1290-1321. May 2014

Andersson E, Tengo M, McPhearson T, Peleg K (2015) Cultural ecosystem services as a gateway for improving urban sustainability. Ecosyst Serv 12:165-168

Avelino F, Rotmans J (2011) A dynamic conceptualization of power for sustainability research. J Clean Prod 19(8):796-804

Aylett A (2010) Conflict, collaboration, and climate change: participatory democracy and urban environmental struggles in Durban, South Africa. Int J Urban Reg Res 34:478-495

Aylett A (2013) Networked urban climate governance: neighborhood-scale residential solar energy systems and the example of Solarize Portland. Environ Plann C Gov Policy 31:858-875

Barr S, Shaw G, Coles T (2011) Sustainable lifestyles: sites, practices, and policy. Environ Plan A 43(12):3011-3029

Borzel TA, Risse T (2010) Governance without a state: can it work? Regul Gov 4:113-134. doi:10.1111/j.1748-5991.2010.01076.x

Boyer RHW (2015) Grassroots innovation for urban sustainability: comparing the diffusion pathways of three ecovillage projects. Environ Plan A 45:320-337

Bratman GN, Daily GC, Levy BJ, Gross JJ (2015) The benefits of nature experience: improved affect and cognition. Landsc Urban Plan 138:41-50

Buchel S, Frantzeskaki N (2015) Citizen's voice: a case study about perceived ecosystem services by urban park users in Rotterdam, The Netherlands. Ecosyst Serv 12:169-177

Burggraeve R (2015) Volunteering and ethical meaningfulness. Found Sci 20(2):1-4

Bussu S, Bartels KPR (2014) Facilitative leadership and the challenge of renewing local democracy in Italy. Int J Urban Reg Res 38(6):2256-2273. doi:10.1111/1468-2427.12070

Calhoun C (2012) The roots of radicalism: tradition, the public sphere, and early nineteenthcentury social movements. The University of Chicago Press, Chicago

Carmin J, Hicks B, Beckmann A (2003) Leveraging local action: grassroots initiatives and transboundary collaboration in the formation of the white Carpathian Euroregion. Int Sociol 18(4):703. doi:10.1177/0268580903184004

Carrus G, Scopelliti M, Lafortezza R, Colangelo G, Ferrini F, Salbitano F, Agrimi M, Portoghesi L, Semenzato P, Sanesi G (2015) Go greener, feel better? The positive effects of biodiversity on the well-being of individuals visiting urban and peri-urban green areas. Landsc Urban Plan 134:221-228

Cerar A (2014) From reaction to initiative: potentials of contributive participation. Urbani izziv 25(1). doi:10.5379/urbani-izziv-en-2014-25-01-002 
Chmutina K, Wiersma B, Goodier CI, Devine-Wright P (2014) Concern or compliance? Drivers of urban decentralized energy initiatives. Sustain Cities Soc 10:122-129

Christmann GB (2014) Investigating spatial transformation processes: an ethnographic discourse analysis in disadvantaged neighbourhoods. Hist Soc Res 39(2):235-256. doi:10.12759/ hsr.39.2014.2.235-256

Coenen L, Truffer B (2012) Places and spaces of sustainability transitions: geographical contributions to an emerging research and policy field. Eur Plan Stud 20(3):367-374

Cote M, Nightingale AJ (2012) Resilience thinking meets social theory: situating social change in socio-ecological systems (SES) research. Prog Hum Geogr 36:475-489

Creamer E (2015) The double-edged sword of grant funding: a study of community-led climate change initiatives in remote rural Scotland. Local Environ 20(9):981-999. doi:10.1080/13549 839.2014.885937

Desa G, Koch JL (2014) Scaling social impact: building sustainable social ventures at the base-ofthe-pyramid. J Soc Entrep 5(2):146-174. doi:10.1080/19420676.2013.871325

Devolder S, Block T (2015) Transition thinking incorporated: towards a new discussion framework on sustainable urban projects. Sustainability 2015(7):3269-3289. doi:10.3390/su7033269

Eckerberg K, Bjarstig T, Zachrisson A (2015) Incentives for collaborative governance: top-down and bottom-up initiatives in the Swedish Mountain region. Mt Res Dev 35(3):289-298

Ernston H (2013) The social production of ecosystem services: a framework for studying environmental justice and ecological complexity in urbanized landscapes. Landsc Urban Plan 109:7-17

Foo K, Martin D, Wool C, Polsky C (2015) The production of urban vacant land: relational placemaking in Boston, MA neighborhoods. Cities 40:175-182

European Commission (2015) Towards an EU research and innovation policy agenda for naturebased solutions \& re-naturing cities. Final report of the Horizon 2020 expert group on "Naturebased solutions and re-naturing cities." Brussels.

Forrest N, Wiek A (2015) Success factors and strategies for sustainability transitions of small-scale communities - evidence from a cross-case analysis. Environ Innov Soc Trans 17:22-40

Frantzeskaki N, Kabisch N (2016) Designing a knowledge co-production operating space for urban environmental governance, lessons from Rotterdam, Netherlands and Berlin, Germany. Environ Sci Pol 62:90-98

Frantzeskaki N, Wittmayer J, Loorbach D (2014) The role of partnerships in 'realizing' urban sustainability in Rotterdam's City Ports Area, the Netherlands. J Clean Prod 65:406-417. doi:10.1016/j.jclepro.2013.09.023

Fraser JC, Kick EL (2014) Governing urban restructuring with city-building nonprofits. Environ Plan A 46:1445-1461

Fuchs G, Hinderer N (2014) Situative governance and energy transitions in a spatial context: case studies from Germany. Energy Sustain Soc 4:16

Garcia M, Eizaguirre S, Pradel M (2015) Social innovation and creativity in cities: a socially inclusive governance approach in two peripheral spaces of Barcelona. City Cult Soc 6:93-100

Gorissen L, Spira F, Meyers E, Velkering P, Frantzeskaki N (2017) Moving towards systemic change? Investigating acceleration dynamics of urban sustainability transitions in the Belgian City of Genk. J Clean Prod. Article in Press.

Green TL, Kronenberg L, Andersson E, Elmqvist T, Gomez-Baggethun E (2016) Insurance value of green infrastructure in and around cities. Ecosystems. doi:10.1007/s10021-016-9986-x

Haase D, Schwarz N, Strohbach M, Kroll F, Seppelt R (2012) Synergies, trade-offs, and losses of ecosystem services in urban regions: an integrated multiscale framework applied to the LeipzigHalle region. Germany Ecol Soc 17(3). doi:10.5751/ES-04853-170322

Healey P (2015) Citizen-generated local development initiative: recent English experience. Int J Urban Sci 19(2):109-118. doi:10.1080/12265934.2014.989892

Healey P, Vigar G (2015) Creating a special place: the Ouseburn valley and trust in Newcastle. Plan Theory Pract 16(4):565-567. doi:10.1080/14649357.2015.1083153 
Horsford SD, Sampson C (2014) Promise neighborhoods: the promise and politics of community capacity as urban school reform. Urban Educ 49(8):955-991. doi:10.1177/0042085914557645

Kabisch N, Frantzeskaki N, Artmann M, Davis M, Haase D, Knapp S, Korn H, Naumann S, Pauleit S, Stadler J, Zaunberger K, Bonn A et al (2016) Nature-based solutions to climate change mitigation and adaptation in urban areas - perspectives on indicators, knowledge gaps, opportunities and barriers for action. Ecol Soc 21(2):39. [online] URL: http://www.ecologyandsociety. org/vol21/iss2/art39/

Kazmierczak A (2013) The contribution of local parks to neighbourhood social ties. Landsc Urban Plan 109:31-44

Kothari A (2014) Radical ecological democracy: a path forward for India and beyond. Development 57(1):36-45. doi:10.1057/dev.2014.43

Magnani N, Osti G (2016) Does civil society matter? Challenges and strategies of grassroots initiatives in Italy's energy transition. Energy Res Soc Sci 13:148-157

Moss T, Becker S, Naumann M (2014) Whose energy transition is it, anyway? Organisation and ownership of the Energiewende in villages, cities and regions. Local Environ 20(12):15471563. doi:10.1080/13549839.2014.915799

Mullaney J, Lucke T, Trueman SJ (2015) A review of benefits and challenges in growing street trees in paved urban environments. Landsc Urban Plan 134:157-166

Olsson P, Galaz V, Boonstra WJ (2014) Sustainability transformations: a resilience perspective. Ecol Soc 19(4):1. doi:10.5751/ES-06799-190401

Reeves A, Lemon M, Cook D (2014) Jump-starting transition? Catalysing grassroots action on climate change. Energ Effic 7:115-132

Romero-Lankao P (2012) Governing carbon and climate in the cities: an overview of policy and planning challenges and options. Eur Plan Stud 20(1):7-26

Rotmans J, Kemp R, Asselt MV (2001) More evolution than revolution: transition management in public policy. Foresight 3:1-17

Sagaris L (2014) Citizen participation for sustainable transport: the case of "Living City" in Santiago, Chile (1997-2012). J Transp Geogr 41:74-83

Seyfang G, Longhurst N (2013) Desperately seeking niches: grassroots innovations and niche development in the community currency field. Glob Environ Chang 23(5):881-891. doi:10.1016/j.gloenvcha.2013.02.007

Seyfang G, Smith A (2007) Grassroots innovations for sustainable development: towards a new research and policy agenda. Environ Polit 16(4):584-603. doi:10.1080/09644010701419121

Seyfang G, Hielscher S, Hargreaves T, Martiskainen M, Smith A (2014) A grassroots sustainable energy niche? Reflections on community energy in the UK. Environ Innov Soc Trans 13:2144. doi:10.1016/j.eist.2014.04.004

Staggenborg S, Ogrodnik C (2015) New environmentalism and Transition Pittsburgh. Environ Polit 24(5):723-741. doi:10.1080/09644016.2015.1027059

Tidball K, Stedman R (2012) Positive dependency and virtuous cycles: from resource dependence to resilience in urban social-ecological systems. Ecol Econ 86:292-299

Touchton M, Wampler B (2014) Improving social well-being through new democratic institutions. Comp Pol Stud 4(10):1442-1469. doi:10.1177/0010414013512601

Van der Brugge R, Van Raak R (2007) Facing the adaptive management challenge: insights from transition management. Ecol Soc 12:33

Verdini G (2015) Is the incipient Chinese civil society playing a role in regenerating historic urban areas? Evidence from Nanjing, Suzhou and Shanghai. Habitat Int 50:366-372

Wagenaar H, Healey P (2015) The transformative potential of civic enterprise. Plan Theory Pract 16(4):557-585. doi:10.1080/14649357.2015.1083153

Walker JS, Koroloff N, Mehess SJ (2014) Community and state systems change associated with the healthy transitions initiative. J Behav Health Serv Res 42:254-271. doi:10.1007/ s11414-014-9452-5 
Warshawsky DN (2014) Civil society and urban food insecurity: analyzing the roles of local food organization in Johannesburg. Urban Geogr 35(1):109-132. doi:10.1080/02723638.2013.860753

Westley FR, Tjornbo O, Schultz L, Olsson P, Folke C, Crona B, Bodin Ö (2013) A theory of transformative agency in linked social-ecological systems. Ecol Soc 18(3):27. doi:10.5751/ ES-05072-180327

Wolfram M, Frantzeskaki N (2016) Cities and systemic change for sustainability: prevailing epistemologies and an emerging research agenda. Sustainability 8. doi:10.3390/su8020144

Zajontz T, Laysens A (2015) Civil society in Southern Africa - transformers from below? J South Afr Stud 41(4):887-904. doi:10.1080/03057070.2015.1060091

Open Access This chapter is licensed under the terms of the Creative Commons Attribution 4.0 International License (http://creativecommons.org/licenses/by/4.0/), which permits use, sharing, adaptation, distribution and reproduction in any medium or format, as long as you give appropriate credit to the original author(s) and the source, provide a link to the Creative Commons license and indicate if changes were made.

The images or other third party material in this chapter are included in the chapter's Creative Commons license, unless indicated otherwise in a credit line to the material. If material is not included in the chapter's Creative Commons license and your intended use is not permitted by statutory regulation or exceeds the permitted use, you will need to obtain permission directly from the copyright holder. 